\title{
Thermal tuning of a thin-film optical filter based on porous silicon and liquid crystal
}

\author{
Tkachenko G.V. and Shulika O.V. \\ Kharkov National University of Radio Electronics, Kharkov, Ukraine, \\ tgogy@mail.ru, a.shulika@ osamember.org
}

Received: 02.07.2010

\begin{abstract}
Spectral characteristics of an interference optical filter based on a free-standing mesoporous silicon film containing nematic liquid crystal E7 are studied experimentally. The porous structure represents two distributed Bragg reflectors divided by a quarter-wave microcavity having a resonance near $1600 \mathrm{~nm}$. Optical transmission spectra of the filter are measured in the temperature range from $27^{\circ} \mathrm{C}$ to $80^{\circ} \mathrm{C}$. For the temperatures less than $62^{\circ} \mathrm{C}$ (a clearing point of the liquid crystal), we have observed continuous red shift of resonant wavelength of the microcavity in the range of $11 \mathrm{~nm}$. The thermal dependence of the shift measured by us has sharply increasing slope near the clearing point. The resonant wavelength of the microcavity exhibits a slow linear decrease for the temperatures exceeding $62^{\circ} \mathrm{C}$. We have also studied the spectra of the filter under local heating of the sample by a laser. Our results demonstrate that the laser beam with the power of $100 \mathrm{~mW}$ provides total tuning of the microcavity.
\end{abstract}

Keywords: porous silicon, microcavity, liquid crystal, thermal tuning, local laser heating

PACS: $42.25 . \mathrm{Hz}, 42.70 . \mathrm{Df}, 42.79 . \mathrm{Ci}$

UDC: $535.345 .67,532.783$

\section{Introduction}

Technology of electrochemical etching of crystalline silicon [1] allows quick and relatively cheap fabrication of thin porous films having desired porosity distribution and pore sizes. The depth distribution of porosity defines the effective refractive index profile of a film. For the near infrared (NIR) wavelength range, the effective refractive index of porous silicon (PSi) can be varied from 1.1 to 3.5, while its optical absorption remains quite low. In this connection multilayer PSi films find their applications in the NIR photonic devices such as distributed Bragg reflectors (DBR) with rugate [2] and step [3] porosity profiles, microcavity structures [3, 4], and nonperiodic photonic quasi-crystals [5].

Open cylindrical pores in the PSi film can be easily filled with different substances which modify its effective refractive index and, consequently, the optical output. This principle is applied in porous biosensors [6]. If the pores are filled with an optically tunable medium, then the optical properties of the PSi sample also become tunable. Liquid crystals (LC) are widely known for their significant optical anisotropy and high sensitivity to external influences like temperature, mechanical strains, and electric or 
magnetic fields. Combination of a LC and multilayer PSi structures have given rise to creation of interference optical filters based on multilayer porous DBRs, with electrically and thermally tunable spectral characteristics $[4,7,8]$.

Porous structures for the devices mentioned above are fabricated by etching electrochemically a crystalline silicon wafer in HF solutions, and than are filled with a LC. However, the devices designed on a wafer have several disadvantages: (1) the wafer is not transparent and so only a reflection mode is available; (2) a stable operation requires capping of LC on the surface but this procedure is rather difficult technically [1, 4]; (3) a pore has only a single open end, so that the LC usually occupies only about $50 \%$ of the pore volume [9]. In this work we suggest a new design: infiltration of LC into a free-standing (FS) PSi film placed in a plane-parallel glass cell. Spectral characteristics and thermal tuning of the NIR interference filter based on such a multilayer porous film are then investigated.

Temperature control would allow easy and reliable tuning of LC-based devices. Still, the process manifests low performance and high energy consumption whenever the tuning requires heating (or cooling) of great volume of the device. Minimising of the heat exchange region can decrease power inputs and enhance a response speed of the device. Local heating of a PSi film within the area of signal ray propagation can reduce linear dimensions of the heated volume down to the thickness of this FS film itself (about $10 \mu \mathrm{m})$. This is why the heat source should be placed inside a porous structure to minimise heating of the glass plates. To solve this problem, we propose to use a powerful visible-light laser beam, which passes the LC and the glasses almost without losses, but is strongly absorbed in the PSi. Spectral characteristics of the interference filter based on this FS PSi and the LC are measured at different values of the laser beam power.

\section{Materials and methods}

A highly doped $p+$-silicon with $<100\rangle$ orientation, $0.01 \Omega / \mathrm{cm}$ resistivity, and $400 \mu \mathrm{m}$ thickness was used as a substrate while fabricating our PSi samples. Silicon wafers were electrochemically etched in an HF-based solution (50 wt \% HF : ethanol = $3: 7$ ) in the conditions of dark and room temperature [7]. The etch process is quasi-linear only for short periods of time [1], because the reaction products cumulate at the etch zone and change the electrolyte concentration. Therefore, pulses of electrical current were applied with the duration of $0.2 \mathrm{~s}$ alternated with the pauses of $5 \mathrm{~s}$. The porosity of a single PSi layer was defined issuing from the value of the corresponding current density, in accordance with the calibration data available in the literature [7-10] (the curves of the porosity and etching rate versus the current density). The thickness of each layer was defined by a quantity of discreet steps performed while etching the layer. The porosity of a layer is known to be related to its effective refractive index.

The structure designed by us has the scheme (LH)*10+(HL)*10, where $\mathrm{H}$ and $\mathrm{L}$ stand for the layers with high and low porosity, respectively. The thickness $d$ of the $i$ th layer fits to the quarter-wave condition for a given resonant wavelength $\lambda$ [11]: 


$$
d_{i}=\frac{\lambda}{\left(4 n_{i} \cos \theta_{i}\right)},
$$

where $n_{i}$ is the effective refractive index of the layer and $\theta_{i}$ the angle of incidence (only the normal incidence, $\theta=0$, is considered in what follows). Thus, the structure consists of two DBRs having 10 half-wave (LH or HL) periods each and represents an interference filter with the first stop band at the resonant wavelength. Periodicity of the structure has some defect in the middle made as a quarter-wave $\mathrm{H}$ layer, which serves as a microcavity and gives rise to a sharp resonant transmission peak at $\lambda$.

In the current research we aim at fabricating a sample having its transmission peak $\lambda$ within the C-band of the optical fibre telecommunication (1530-1565 nm). For this purpose we have calculated the parameters of a multilayer composite medium containing three substances (the air, silicon, and the LC) and meeting the condition given by Eq. (1). The presence of the LC complicates these calculations because of the two reasons: (1) anisotropy of the LC requires taking a spatial director distribution in pores into account, and (2) the volume fraction of the LC in the composite is unknown. Therefore all the calculations were performed for the LC being in its isotropic phase and occupying $80 \%$ of the pore volume $[7,8]$. The effective dielectric permittivity $\varepsilon$ of each layer was calculated using the Bruggeman effective medium approximation (EMA) for the three media [12]:

$$
\frac{\varepsilon_{S i}-\varepsilon}{\varepsilon_{S i}+2 \varepsilon} p_{S i}+\frac{\varepsilon_{\text {air }}-\varepsilon}{\varepsilon_{\text {air }}+2 \varepsilon} p_{\text {air }}+\frac{\varepsilon_{L C}-\varepsilon}{\varepsilon_{L C}+2 \varepsilon} p_{L C}=0,
$$

where $\varepsilon_{S i}, \varepsilon_{a i r}$ and $\varepsilon_{L C}$ are the dielectric permittivities of the silicon, the air and the LC, respectively, and $p_{S i}, p_{\text {air }}$ and $p_{L C}$ denote the corresponding volume fractions of these media in the composite. Well-known dispersion curves for the dielectric permittivities $\varepsilon_{S i}$ and $\varepsilon_{L C}$ were used during our calculations of $\varepsilon$. Since the composite was non-magnetic $(\mu=1)$, the effective refractive index of a layer was equal to $\varepsilon^{1 / 2}$ [11].

Thicknesses of the porous layers were found using Eq. (1). Several multilayer PSi structures were fabricated according to the following recipe: (1) the porosity $76 \%$, etch rate $160 \mathrm{~nm} / \mathrm{s}$, and 7 cycles with the current density of $250 \mathrm{~mA} / \mathrm{cm}^{2}$ for the $\mathrm{H}$ layer, and (2) the porosity $61 \%$, etch rate $63 \mathrm{~nm} / \mathrm{s}$, and 14 cycles with the current density of $80 \mathrm{~mA} / \mathrm{cm}^{2}$ for the L layer. The top and cross-section views of the samples (see Fig. 1a and Fig. 1b, respectively) were made using a scanning electron microscope with a field emission gun (SEM-FEG Gemini 300, Carl Zeiss). Using the photos shown in Fig 1, we have assumed that the pores etched have the average diameter of $50 \mathrm{~nm}$, which corresponds to a threshold between the mesopores $(2-50 \mathrm{~nm}$ ) and macropores (over $50 \mathrm{~nm}$ ) [1]. These pores are very convenient for creating PSi-based tunable optoelectronic devices for the NIR range, since they are wide enough for good infiltration with active liquids and, at the same time, their diameter is much less than the operating wavelength. As a consequence, the porous composite behaves as an isotropic medium and can be adequately simulated using the EMA. 

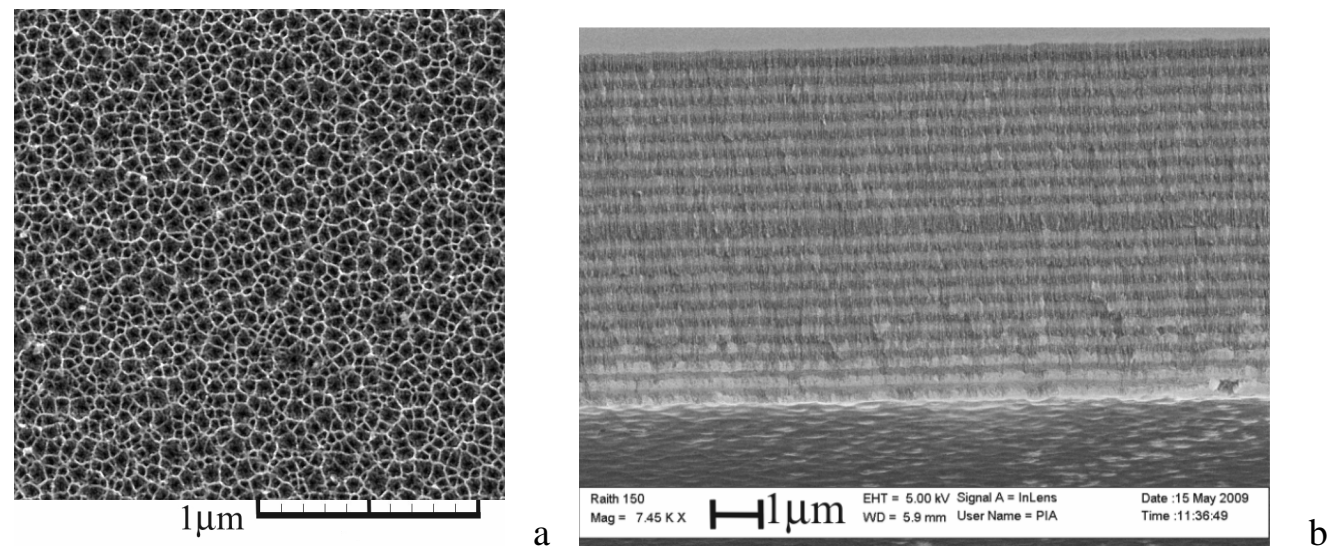

Fig. 1. SEM-FEG pictures of the PSi sample fabricated by us.

The multilayer PSi samples thus fabricated were made FS by means of the Turner "lift-off" technique [13]: the current density was ramped to $800 \mathrm{~mA} / \mathrm{cm}^{2}$ at the end of the etch process. The latter value corresponds to electro-polishing mode and results in detachment of PSi film from the substrate. The technique allows one to fabricate several FS structures on the same wafer, without disassembling of anodisation cell. The first sample, being etched directly from the wafer surface, has bottle-shaped pores [1, 6] and the top nanoporous layer (a few nanometres thick) gradually turns into the mesoporous Si. Nonuniformity of the structure causes strong mechanical strains and damage of the FS film during electro-polishing. Thus, the first sample is auxiliary: tips of the etched pores remain on the Si surface [6], then a new etching process starts in these tips, and all the next samples are etched without nanopores. Each pore in the FS film is open from both ends, so it can be easily filled with the LC. Treatment of the fresh samples with the $\mathrm{KOH} /$ ethanol solution for $15 \mathrm{~min}$ enlarges the pores [5] and slightly improves infiltration of the LC.

The FS PSi film thus fabricated (see Fig. 2) was placed between two flat-parallel glass plates separated by $12 \mu \mathrm{m}$ thick mylar stripes (2-3 $\mu \mathrm{m}$ thicker than the PSi film). Then the glass cell was infiltrated under vacuum with a nematic LC mixture E7 in its isotropic phase. Low pressures provided removal of both air and moisture from the LC, while high temperatures reduced its viscosity and so enhanced the infiltration. Finally, the cell was sealed up with an ultraviolet adhesive glue NOA68.
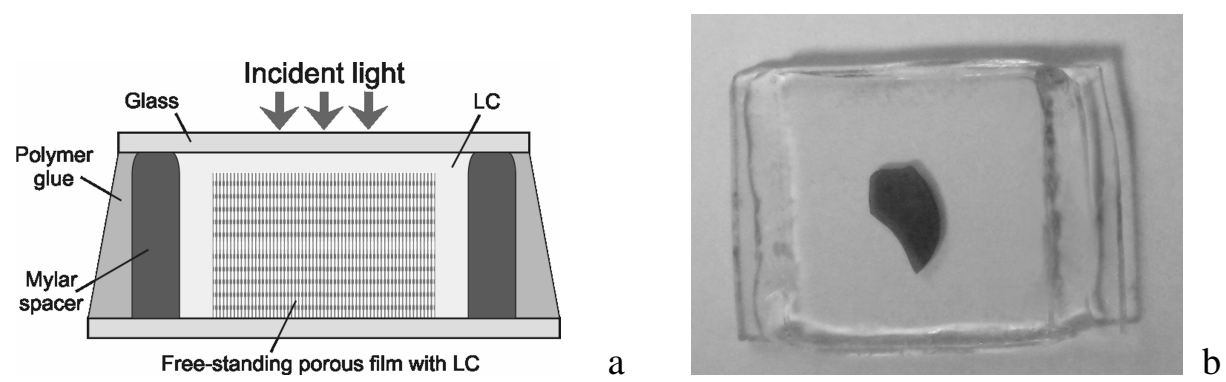

Fig. 2. Scheme (a) and top-view picture (b) of experimental sample under study.

Ukr. J. Phys. Opt. 2010, V11, №4 
Spectral characteristics of the sample were measured using a variable-angle spectroscopic ellipsometer VASE® from J.A. Woolam Company. A monochromator of VASE® had the operating wavelength range from 270 to $1700 \mathrm{~nm}$ and the spectral resolution of up to $2 \mathrm{~nm}$. We used a fitting facility of WVASE32® software to specify the parameters of the multilayered PSi structure and the LC confined in it. During the measurements, the PSi-based interference filter was placed in a hot stage from CaLCTec S.R.l., which was mounted on the sample holder of VASE®. The hot stage was able to control sample temperature in the range from the room temperature up to $200^{\circ} \mathrm{C}$ with the accuracy of $0.1{ }^{\circ} \mathrm{C}$. We investigated also local sample heating by means of Ventus 532 (Laser Quantum), with a continuous operation at $532 \mathrm{~nm}$. The size of the laser beam spot was controlled using a collecting lens with a $10 \mathrm{~cm}$ focus. The output power of the laser was governed by the power supply current and was measured in front of the sample by a power and energy meter Nova (Ophir Optronics Ltd.).

\section{Results and discussion}

The transmission spectrum measured for the empty FS PSi film is shown in Fig. 3a by dots. The spectrum is typical for the Bragg reflectors: one can see the stop band in the range of $1180-1450 \mathrm{~nm}$, and a number of side lobes. A presence of microcavity explains a sharp transmission peak located within the stop band at $1291 \mathrm{~nm}$.
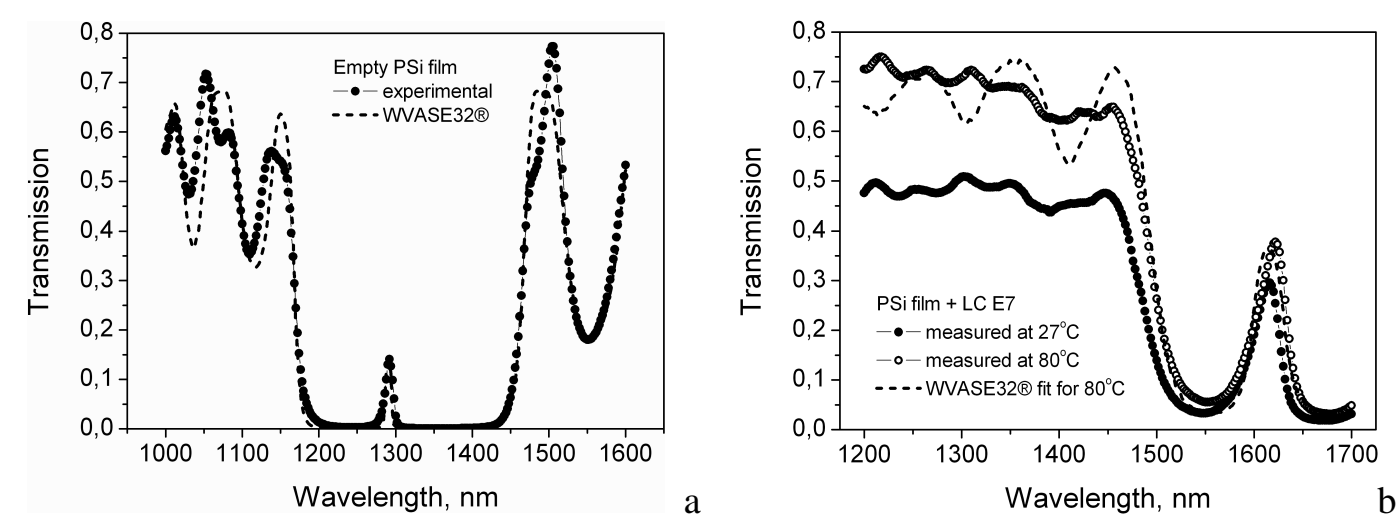

Fig. 3. Transmission spectra measured and fitted for the cases of (a) empty experimental sample and (b) sample filled with E7 (in the nematic and isotropic phases).

The analysis of our experimental data has been performed using the WVASE32 ${ }^{\circ}$ software. The optical model of the structure under test contains all of its layers, including the glass plates and the 2-3 $\mu \mathrm{m}$ thick LC layer above the filled PSi film. The porous film is represented by a stack of uniform layers, with the effective refractive indices determined by means of the Bruggeman EMA. The geometry of the porous structure (i.e., the porosity and the thickness of the layers) has been obtained by the fitting procedure that matches the curves generated by the model (see the dashed line in Fig. 3a) with the experimental data. The procedure is based on minimising the mean square deviation. We 
have found the following porosities: $78.4 \%$ for the $\mathrm{H}$ and $62.3 \%$ for the $\mathrm{L}$ layers. Their deviations from the values $76 \%$ and $61 \%$ implied in the fabrication recipe are caused by imperfections of the calibration data. The fitted thicknesses are $228 \mathrm{~nm}$ for the $\mathrm{H}$ and 191 $\mathrm{nm}$ for the L layers.

The transmission spectra of the sample after its infiltration with E7 were measured at $27^{\circ} \mathrm{C}$ and $80^{\circ} \mathrm{C}$ (see respectively the dots and circles in Fig. 3b). The lower temperature value corresponds to the nematic phase and higher to a deep isotropic phase of E7. As seen from Fig. 3, the resonant peak of the microcavity is shifted by $328 \mathrm{~nm}$ towards the red side if compare to the spectrum taken before the LC infiltration. This shift is caused by increase in the effective refractive indices of the porous layers occurring after substitution of air with the LC. The transmission of the sample containing the $\mathrm{LC}$ at $27^{\circ} \mathrm{C}$ is noticeably lower than that for the empty structure. In our opinion, this fact can be explained by light scattering taking place within a relatively thick unaligned LC layer between the PSi film and the upper glass. As against the spectrum for $27^{\circ} \mathrm{C}$, the dependence observed at $80^{\circ} \mathrm{C}$ is slightly red-shifted and the corresponding transmission level approaches that for the empty sample, because of clearing of the LC.

A red shift of the microcavity resonance points to increasing effective refractive index of the LC in the pores, owing to nematic-isotropic phase transition. The dashed line in Fig. $3 \mathrm{~b}$ represents the transmission spectrum generated by WVASE32 $®$ for $80^{\circ} \mathrm{C}$. The volume fraction of the isotropic LC has been found using the fit procedure, while the geometry of the porous structure has been kept constant. The best fit corresponds to the LC volume fractions relative to an empty pore volume (i.e., $\left.p_{L C} /\left(1-p_{S i}\right)\right)$ of $84 \%$ and $71 \%$ for the $\mathrm{H}$ and $\mathrm{L}$ layers, respectively. These values are significantly higher than $50 \%$, which is common for on-wafer PSi structures [4, 9]. Thus, we have proved experimentally that the FS-based designs provide better LC infiltration. This aspect is very important for the tunable devices since the amount of the active medium would define the tuning range.

The measured temperature dependence of the microcavity resonance shift is plotted in Fig. 4. The shift increases nonlinearly with temperature and the slope of the dependence sharply increases near $63^{\circ} \mathrm{C}$. For the temperatures higher than $63^{\circ} \mathrm{C}$ the resonant wavelength of the microcavity exhibits a slow linear decrease (the approximation is shown by the dashed line), which is typical for the isotropic E7 in a bulk cell [14]. We have observed reversible and quite reproducible thermal tuning of the sample in the range of $11 \mathrm{~nm}$.

The spectral characteristics are measured within a small area of incident signal beam. In other words, tuning of the FS PSi-based interference filter does not require heating of the whole sample and the glass cell and so only small volume of the LC should be heated. In this work we have studied the prospects for local heating of the operation area by means of a laser beam. First, we have measured the spectra of the filter under investigation at the room temperature $\left(27^{\circ} \mathrm{C}\right)$. They have remained invariable up to the power value of $180 \mathrm{~mW}$. Still higher powers have been probed, resulting in darkening 


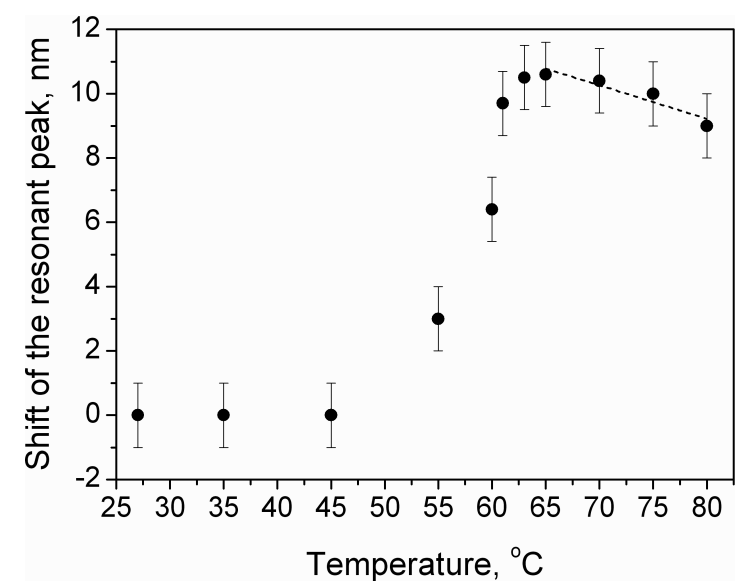

Fig. 4. Shift of the microcavity resonance versus temperature.

surface of the PSi film within the laser beam spot. It is apparent that the porous structure has become damaged under these conditions. Aiming to protect the sample from a thermal shock, we have displaced the collecting lens so that the laser spot has increased up to $2 \mathrm{~mm}$. Then the temperature of the hot stage has been raised up to $47^{\circ} \mathrm{C}$. Such a heating does not affect the spectrum, as evident from Fig. 4, though it should decrease the laser power required for tuning the filter. Fig. 5a shows the spectra of the investigated sample referred to the zero laser power (dots) and the power of $100 \mathrm{~mW}$ (circles). Here the dashed lines show the positions of maxima of the microcavity resonance peaks. It is seen that the power of $100 \mathrm{~mW}$ provides a red shift of the resonance peak by $11 \mathrm{~nm}$, which corresponds to the nematic-isotropic phase transition in E7, as stated above. The results for the shift of the resonance peak are presented in Fig. 5b. This dependence is evidently similar to that displayed in Fig. 4.
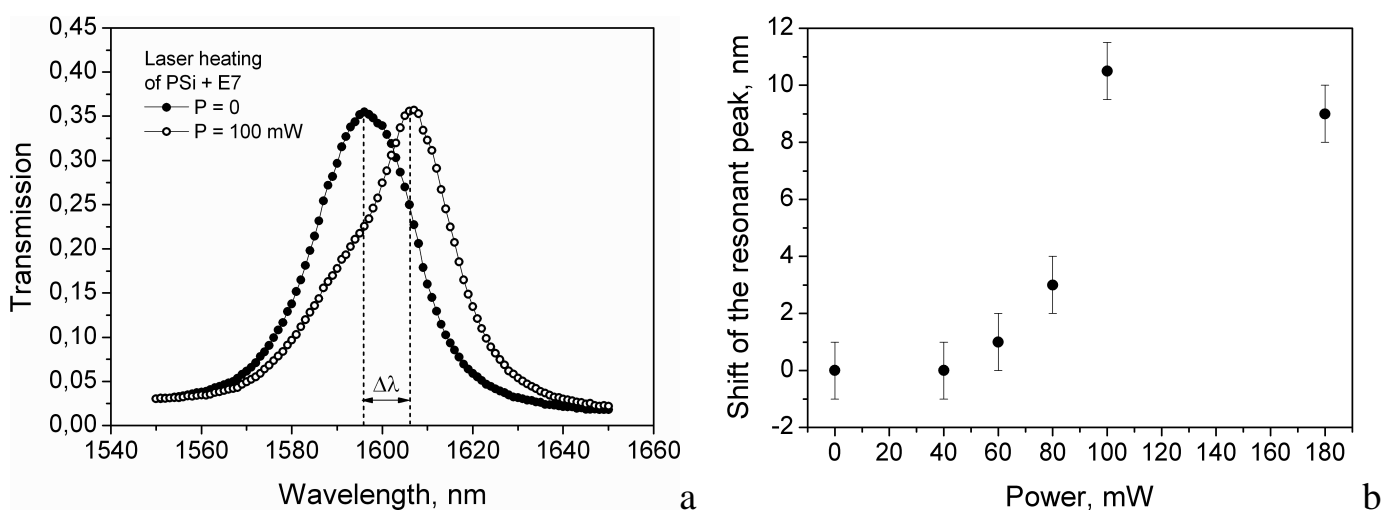

Fig. 5. Experimental spectra of the filter under study for the two extreme laser powers (a) and dependence of the microcavity resonance shift upon the laser power (b).

Local laser heating gives some prospects for independent tuning of different parts of the same sample, acting as individual thermooptic filters. As a result, the overall size of the tunable devices and the expended material would decrease substantially. Moreover, 
heating or cooling of a small volume occurs much faster than that for the whole structure. Thus, we expect an increase of performance for the laser driven LC-based optical devices by one or two orders of magnitude. The threshold laser power required for total tuning of these devices depends on the size of heated area, the absorption strength in the medium, and the losses imposed by reflection from the cell surface (about 30\% for the oblique incidence on the glass [11]). Consequently, the threshold power can be lowered by means of antireflection coatings, laser beam focusing, and by combining the LC with dyes for the visible light.

\section{Conclusions}

We have fabricated and characterised optically an interference NIR filter. The device contains a thin FS film of multilayer mesoporous silicon, forming a microcavity structure filled with a nematic liquid crystal mixture E7. Thermal dependence of the spectral characteristics of that filter has been investigated. We have observed a reversible red shift of the microcavity transmission peak in the range of $11 \mathrm{~nm}$.

We have found that the nematic LC occupies $84 \%$ of the pore volume in the FS mesoporous silicon. This value is much higher than that obtained for the mesoporous silicon on wafers. The FS PSi film enables operation of the device both in the reflection and transmission modes, while the on-wafer designs are not transparent in the optical range. Thus, the porous FS film technology has much more prospects for different LCbased photonic applications than the on-wafer ones developed previously.

Local laser heating of the LC in pores has been suggested for tuning our optical filter. We have found out that the $100 \mathrm{~mW}$ laser beam provides total tuning of that filter. Some recommendations regarding lowering of the laser power threshold are given.

\section{Acknowledgements}

The authors would like to thank Dr. Ilaria Rea and Dr. Luca de Stefano from the Institute of Microelectronics and Microsystems (IMM-CNR, Naples, Italy) for their help with fabrication of PSi samples, and Dr. Vladimir Tkachenko from University of Federico II (Naples, Italy) for his great assistance with the ellipsometry and the laser-heating plant assemblage.

\section{References}

1. Canham L. Properties of porous silicon. London: Inspec/IEE (1997).

2. Lorenzo E, Oton C J, Capuj N E, Ghulinyan M, Navarro-Urrios D, Gaburro Z and Pavesi L, 2005. Fabrication and optimization of rugate filters based on porous silicon. Phys. Stat. Solidi (c). 2: 3227-3231.

3. Ghulinyan M, Oton C, Bonetti G, Gaburro Z and Pavesi L, 2003. Free standing porous silicon single and multiple optical cavities. J. Appl. Phys. 93: 9724-9729.

4. Weiss $S$, Ouyang $H$, Zhang $J$ and Fauchet $P$, 2005. Electrical and thermal modulation of silicon photonic bandgap microcavities containing liquid crystals. Opt. Express. 13: 1090-1097. 
5. Moretti L, Rea I, Rotiroti L, Rendina I, Abbate G, Marino A and De Stefano L, 2006. Photonic band gaps analysis of Thue-Morse multilayers made of porous silicon. Opt. Express. 13: 6264-6272.

6. Ouyang H, Christophersen M, Viard R, Miller B and Fauchet P, 2005. Macroporous silicon microcavities for macromolecule detection. Adv. Functional Mater. 15: 18511859.

7. Tkachenko G, Tkachenko V, De Stefano L and Sukhoivanov I, 2009. Tunable NIR filter based on a free-standing porous silicon film containing nematic liquid crystal. J. Opt. A: Pure Appl. Opt. 11: 105106.

8. Tkachenko G, Tkachenko V, Abbate G, De Stefano L, Rea I and Sukhoivanov I. New developments in liquid crystals. Vukovar: In-Teh (2009).

9. Marino A, Abbate G, Tkachenko V, Rea I, De Stefano L and Giocondo M, 2007. Ellipsometric study of liquid crystal infiltrated porous silicon. Mol. Cryst. Liq. Cryst. 465: $359-370$.

10. Tkachenko G, 2010. Ellipsometric study of porous silicon and silica films infiltrated with nematic liquid crystal. Radiotekhnika. 160: 273-279.

11. Born M. and Wolf E. Principles of optics. New York: Cambridge University Press (1999).

12. Spanier $\mathbf{J}$ and Herman I, 2000. Use of hybrid phenomenological and statistical effective-medium theories of dielectric functions to model the infrared reflectance of porous SiC films. Phys. Rev. B. 61: 10437-10450.

13. Turner D, 1958. Electropolishing silicon in hydrofluoric acid solutions. J. Electrochem. Soc. 105: 402-408.

14. Li J, Wu S, Brugioni S, Meticci R and Faetti S, 2005. Infrared refractive indices of liquid crystals. J. Appl. Phys. 97: 073501.

Tkachenko G. V. and Shulika O. V., 2010. Thermal tuning of a thin-film optical filter based on porous silicon and liquid crystal. Ukr.J.Phys.Opt. 11: 260-268.

Анотація. Експериментально досліджені спектральні характеристики інтерференційного оптичного фільтра, який базується на кремнісвих відокремлених, мезопористих плівках, що містять нематичний рідкий кристал Е7. Пориста структура складається з двох розподілених брегівських відбивачів, розділених чверть хвильовим мікрорезонатором з резонансом в околі 1600 нм. Спектри пропускання фільтра досліджені в температурній області від $27^{\circ} \mathrm{C}$ до $80^{\circ} \mathrm{C}$. Для температур нижчих від $62^{\circ} \mathrm{C}$ (температура просвітлення рідкого кристалу), спостерігалось неперервне червоне зміщення резонансної довжини хвилі в області 11 нм. Температурна залежність зміщення є різко зростаючою в околі точки просвітлення. Резонансна довжина хвилі проявляє повільне температурне зменшення для температур, що перевишують $62^{\circ} \mathrm{C}$. В роботі також досліджувались спектральні характеристики фільтра при локальному нагріві зразка лазерним променем. Результати свідчать про те, що вилив лазерного променя з потужністю 100 мВт забезпечує повне перестроювання мікро резонатора. 